\title{
Analysis of Growth and Physiological Variations Among Cyclocarya Species of Different Genotypes in a Clonal Seed Orchard
}

\author{
Xiaofeng Li \\ Quanzhou Normal University \\ Junpo Huang \\ Quanzhou Normal University \\ Guangxin Lin \\ Quanzhou Normal University \\ Xinyu Yang \\ Quanzhou Normal University \\ Chenqi Zheng \\ Quanzhou Normal University
}

Ying Feng ( $\sim$ fengy0919@126.com )

School of Resource and Environmental Science, Quanzhou Normal University, Fujian 362000 (P. R. China)

\section{Research}

Keywords: Cyclocarya paliurus, ex situ conservation, plant growth, physiological change

Posted Date: December 18th, 2020

Dol: https://doi.org/10.21203/rs.3.rs-127476/v1

License: () (i) This work is licensed under a Creative Commons Attribution 4.0 International License. Read Full License 


\section{Abstract}

Background: Cyclocarya paliurus (C. paliurus) is a woody species that has many medical benefits to human health. Geographical species has been formed among different natural forests of $C$. paliurus, but gradually decrease or extinct by human's excessively exploitation in recent years. So, it is worthy to conserve this native and valuable species in China. Environmental factors affected plant growth, and seed is the only way for breeding offspring among Cyclocarya species, herein, we assess plant growth of six genotypes (FJ, JX, TG, WF, JH, AJ) from 2017 to 2019 year and physiological variations from April to October in 2018 during the construction of a clonal seed orchard.

Results: The survival rate of plant reached $100 \%$ in a C. paliurus seed orchard. Plant height and basal diameter varied in different genotypes. Plant of six genotypes had different changes in water content and total soluble sugar content from April to October, Ca content reached maximum among the four detected mineral content, four kinds of antioxidant enzyme activity was in order of SOD『PPOهPOD®CAT, and the highest content of phytochemical was total flavonoid. Plant growth and physiological changes during growth period was significantly correlated with environment factors by correlation analysis.

Conclusions: Plants of ex situ conservation adapted changeable environmental factors by physiological changes and showed the differentiation of plant growth in a clonal seed orchard. This would provide a foundation for ex situ conservation management in Cyclocarya species and selection of suitable cultivation provenance.

\section{Background}

Forest is one of the major natural resources and has important role on economy, ecology and social. With the rapid development of human population and industry, forest resource has undergone massive destruction mainly due to over-exploitation, overgrazing, unsustainable practices, forest fires and environment-unfriendly development projects (Glikson et al. 2012, Karthikeya et al. 2007), which is much beyond the regenerative ability of forest (Bahu et al. 2015). These lead to the decrease of forest diversity and the extinction of many forest resources. Cyclocarya paliurus (Batal.) Iljinskaja (C. paliurus) is a native and unique species distributed in highland of sub-tropical areas in China (Fang et al. 2006). During the long history of evolution and development, the geographical differentiation is formed among Cyclocarya species (Li et al. 2017) and natural forests sporadic distributed in China.

As a material for food industry and medicinal value, $C$. paliurus has been demonstrated to possess a myriad of human health benefits like anticancer, antimicrobial, antihyperlipidemic, antioxidant and anti-inflammatory, which is primarily due to biological activities of various phytochemical in leaf (Xiong et al. 2018, Shang et al. 2018, Liu et al. 2018a, 2018b, Wang et al. 2017, Jiang et al. 2014, Xie et al. 2012, 2013). For obtaining these benefits, natural forests of $C$. paliurus were damaged by human's activity to meet the huge demand of leaf production in the past years. And the lower regeneration of natural forest could further cause this valuable species to be extinct in the future. Now, natural forest of $C$. paliurus is now protected with different conservation status: critically endangered, server convention and convention (http://www. iplant. cn). Therefore, it is very urgent and important to establish an effective way of conserving Cyclocarya species.

Ex situ conservation is an effective way for preserving the extinct or endangered plant species in order to rescue the natural heritage of plant biodiversity (Pritchard et al. 2010, Corlett 2016). A clonal seed orchard (CSO), one of ex situ conservation strategy, often cultivated trees collected from a single provenance or multiple provenances to achieve genetic gain (Chaloupkova et al. 2019, Giertych 1975, Zobel et al. 1958). In C. paliurus, isolation and diverse biological activities of phytochemical from leaf was one of numerous researches about C. paliurus (Peng et al. 2019, Cao et al. 2017, Zhu et al. 2015), another were mainly focused on the increase of phytochemical accumulation in leaf by improving cultivated conditions (Deng et al. 2019a, 2019b, 2017, 2015, Yang et al. 2017, Liu et al. 2018a, 2018b). However, researches about conserving Cyclocarya species were very few. Up to date, seed is the only way for breeding offspring of Cyclocarya species, and CSO would be a suitable way for conserving Cyclocarya species. However, environmental factors affect on plant adaptation (Enßlin et al. 2011; Cao et al. 2018), which could be impact on the successful construction of CSO among Cyclocarya species.

Hence, based on the collection of seed from different species of $C$. paliurus, this study investigated growth variation in physiological changes during the process of CSO construction, and analyzed the relation between environmental factors in the CSO and plant growth. This could be benefit to assess their adaptation in the ex situ conservation and make a solid foundation for selecting superior family for breeding new species and suitable cultivation species.

\section{Methods}

\section{plant materials and site description}

Seeds of $C$. paliurus from six genotypes were collected from natural forests in late October 2015 according to the method described by Deng et al. (2014) and information about six genotypes was seen in Fig.1. The collected seed were first subjected to removing wings, followed by exogenous gibberellin A3 (GA3) treatment, and then stratification treatment using a method described by Fang et al. (2006). After 5 months, the germinated seedlings were transplanted in cultivate bags $(10.8 \mathrm{~cm}$ in diameter and $14.5 \mathrm{~cm}$ in height) and then kept in the nursery (Yongchun, Fujian, China). Each bag had a single plant.

1-year-old plants were selected with even growth and then transplanted to CSO in Xiayang, Fujian on March 2017 with a spacing of $2 \times 2 \mathrm{~m}$. 50 plants of every genotype were conserved in each block. During the experimental period, environmental factors were collected from a local weather bureau and every index was seen in Tab.1.

After 1-year ex situ conservation, leaf samples were collected from the middle part of the current branch on April, June, August and October in 2018. Fresh leaves were divided into two parts, one was used for determining water content (WC), total soluble sugar content (TSS) and antioxidant enzyme activity 
(superoxide dismutase [SOD], peroxidase [POD], catalase [CAT], polyphenol oxidase[PPO]), another was dried to constant weight and then used for investigating mineral content (potassium [K], calcium[Ca], magnesium[Mg],sodium[Na]) and phytochemical content (total flavonoid, total triterpenoid and polysaccharides). Each experiment was repeated three times.

\section{Plant growth index determination}

In April, 2017, all plants were observed and the initial height (named $\mathrm{H}_{\mathrm{i}}$ ) and initial basal diameter (named $\mathrm{BD}_{\mathrm{i}}$ ) were measured, then all surviving plants was observed and plant height (named $\mathrm{H}_{\mathrm{a}}$ ) and basal diameter (named $\mathrm{BD}_{\mathrm{a}}$ ) were measured again in December 2017. The conduction of measurement method in 2018 and in 2019 was the same as that in 2017. The growth index was calculated as:

Net height of each surviving plant $=\mathrm{H}_{\mathrm{a}}-\mathrm{H}_{\mathrm{i}}$

Net $\mathrm{BD}$ of each surviving plant $=\mathrm{BD}_{\mathrm{a}}-\mathrm{BD}_{\mathrm{i}}$

Average net height=the sum of net height among the surviving plants/The number of surviving plants

Average net $\mathrm{BD}=$ the sum of net $\mathrm{BD}$ among the surviving plants/The number of surviving plants

\section{Physiological index determination}

\section{Determination of water content}

According to the method described by Stein et al. (1975), WC of leaves was calculated as WC $(\%)=(F W-D W) / F W \times 100$, where FW mean fresh weight (FW) of leaf, DW mean constant weight of dried leaf (DW).

Extraction and determination of total soluble sugar

Total soluble sugar (TSS) was extracted and determined by Li et al. $(2000)$, then calculated as following: Leaf TSS content $(\%)=(\mathrm{C} \times 25) /\left(\mathrm{W} \times 0.5 \times 10^{6}\right) \times 100$, where $\mathrm{C}$ was obtained from standard curve and sugar was used as standard curve; W mean the weight of fresh sample.

\section{Extraction and determination of mineral content}

Samples were digested by electric-heating digestion method described by Feng et al. (2020). Mineral content (K, Na, Ca, Mg) was calculated by (Cx 0.025)/DW, where C mean its concentration measured by ICP-OES (optima 7000DV, American), DW mean dried weight of sample.

\section{Extraction and analysis of antioxidant enzyme activity}

Antioxidant enzyme was extracted and four kinds of antioxidant enzyme (CAT, SOD, PPO and POD) activity were analyzed in accordance with the method of Feng et al. (2020).

\section{Extraction and analysis of phytochemical content}

Extraction was obtained using an ultrasonic-assisted method with a slight modification (Liu et al. 2018c). Each sample (about $1.0 \mathrm{~g}$ ) was added to $20 \mathrm{~mL}$ $75 \%$ ethanol, then centrifuged at $25^{\circ} \mathrm{C}, 11000 \mathrm{~g}$ for $15 \mathrm{~min}$ after heating at $70^{\circ} \mathrm{C}$ for $60 \mathrm{~min}$ with ultrasonic cleaner (KQ-800DE, China), and finally extraction was obtained.

Total flavonoid content was determined by method described by Liu et al. (2018c), then calculated by the standard rutin curve and expressed as milligrams rutin equivalent per gram of dry mass $(\mathrm{mg} / \mathrm{g})$.

Total triterpenoid content was assessed by using the Folin-Ciocalteu colorimetric method and then expressed as milligrams gallic acid equivalent per gram of dry mass $(\mathrm{mg} / \mathrm{g})$.

Polysaccharides content was conducted by the method described by Liu et al. (2018a), then calculated using the standard glucose curve and expressed as milligrams glucose equivalent per gram of dry mass $(\mathrm{mg} / \mathrm{g})$.

\section{Results}

\section{Analysis of plant growth}

Plant height and basal diameter grew faster after been cultivated one year later. Plant growth varied with different genotypes, FJ had the highest plant height but WF had the highest basal diameter up to 2019 (Tab.2).

\section{Analysis of water content}

WC in leaf was different with growth periods and genotypes. WC change was similar from June to October among FJ, AJ, TG, JX and WF. WC of JH gradually decreased and had the highest content on June (Fig.2). 


\section{Analysis of total soluble sugar content}

Plants of different genotypes varied in TSS content during growth period. TSS content of FJ and JH had the highest value on August, of which change was opposite with that of AJ. TSS content of JX and TG gradually increased and reached maximum on October, which was contrary with that of WF (Fig.3).

\section{Analysis of mineral content}

$\mathrm{K}, \mathrm{Ca}$, Na and $\mathrm{Mg}$ were contained in leaves among 6 genotypes, the highest content was $\mathrm{Ca}(\geq 6.0 \mathrm{mg} / \mathrm{g})$, and then was $\mathrm{K}(\geq 3.0 \mathrm{mg} / \mathrm{g})$, finally was $\mathrm{Mg}$ and $\mathrm{Na}(\leq 2.0 \mathrm{mg} / \mathrm{g})($ Fig.4).

\section{Analysis of antioxidant enzyme activity}

Four kinds of antioxidant enzyme activity was in order of SOD囚PPO囚POD®CAT. However, every antioxidant enzyme of different genotypes had different activity in growth period (Fig.5).

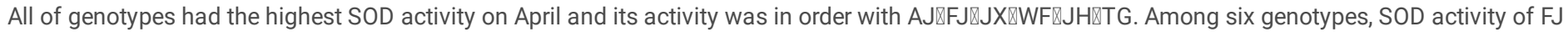
gradually decreased from April to October and similar change exit among FJ, JX and TG. SOD activity among WF, AJ and JH firstly decreased, then increased and finally decreased.

PPO activity of FJ was $30.04 \mathrm{U} /(\mathrm{g} \cdot \mathrm{min})$ on June and reached significant difference with others, of which change was contrary with that of AJ. Both of JX and $\mathrm{JH}$ had similar change of PPO activity and reached maximum on August. PPO activity of TG and of WF reached maximum on October, on August, respectively.

The different peak of POD activity was observed among six genotypes, both of JX and FJ had more than $3.0 \mathrm{U} /(\mathrm{g} \cdot \mathrm{min})$ on June, TG and JH had the highest activity on April and on October, respectively. There was similar change among FJ, JX, TG and JH, but AJ had an opposite change with WF.

CAT activity of JX and FJ was lower than $0.5 \mathrm{U} /(\mathrm{g} \cdot \mathrm{min})$ from April to October. Similar change was found between TG and JH, but its activity of TG was higher than that of $\mathrm{JH}$. AJ and WF reached maximum on August and on June, respectively, and the peak was more than $2.0 \mathrm{U} /(\mathrm{g} \cdot \mathrm{min})$.

\section{Analysis of phytochemical accumulation}

High content of total flavonoid and polysaccharides $(\geq 40 \mathrm{mg} / \mathrm{g}$ ) was detected, but total tritenpenoid content was found in lower amount $(\leq 3.0 \mathrm{mg} / \mathrm{g})$ in $e x$ situ conserved plants. The change of their content varied with growth period and genotypes (Fig.6).

Total flavonoid content of FJ firstly decreased and then increased from April to October, which was similar with that among JX, WF and AJ. However, there was no significant difference from June to October in JH and in TG.

Polysaccharides content of FJ reached $100.16 \mathrm{mg} / \mathrm{g}$ on April, compared with that, its content decreased by $50.52 \%, 57.29 \%$ and $20.39 \%$ from June to October, respectively. Other five genotypes had the highest content of polysaccharides on October, there was similar change between WF and AJ, between $\mathrm{JH}$ and TG.

The highest content of total triterpenoid reached on August among FJ, JX, JH and TG; and their changes were similar, but were contrary with that of WF and AJ. AJ had no significant difference in triterpenoid content from June to October, similar results were observed in WF and in JX.

\section{Correlation analysis among parameters}

Plant height was significantly related with basal diameter, both of them were also related with AT, AP and AS (Tab.3).

Both of $\mathrm{T}$ and $\mathrm{P}$ seemed predominantly impact on various physiological index, (Fig.7). In conformity with CCA, both of T and P was significantly correlated with $\mathrm{K}, \mathrm{Ca}$, polysaccharides and total flavonoid. S had correlation with POD and WC (Tab.4).

There was significant correlation between total triterpenoid and $\mathrm{Mg}$, between $\mathrm{Na}$ and $\mathrm{Ca}$, between $\mathrm{K}$ and SOD activity, between $\mathrm{K}$ and $\mathrm{Na}$. WC had significant correlated with $\mathrm{K}, \mathrm{Ca}$ and TT. Total flavonoid was also related with $\mathrm{Na}, \mathrm{Ca}$ and TP (Tab.4). The similarities are presented in cluster analysis (Fig.8).

\section{Discussions}

Plant growth is influenced by genotype and environment (Enßlin et al. 2011). From our findings, plant height and basal diameter among six genotypes were significantly correlated with environmental factors (annual sunshine hours (AS), annual average temperature (AT) and annual precipitation (AP) (Tab.3), which was disagreement with the finding of Deng et al. (2015) whose findings indicated environmental factors were not correlated with height growth of $C$. paliurus. This could be caused by difference in cultivation sites and genotypes.

As an essential macroelement for plants growth, mineral elements $(\mathrm{K}, \mathrm{Ca}, \mathrm{Mg}$ and $\mathrm{Na}$ ) have an important role in physiological functions, like osmotic adjustments, water balance, water use efficiency improvement and stomata control (Coskun et al. 2013, Gattward et al. 2012, Schachtman et al. 1997). Environmental factors affected mineral uptake and distribution from soil to leaf in plants (Baghour et al. 2002, 2003), this was in agreement with our findings that mineral content varied with growth period and had significant negative relation with temperature and precipitation (Tab.4, Fig.7). 
Plants have developed antioxidant defense systems to adapt changeable environmental factors during growth period. In the enzymatic defense mechanism, SOD, in combination with CAT, PPO and POD, eliminated excessive $\mathrm{H}_{2} \mathrm{O}_{2}$ and $\mathrm{O}_{2}$ in tissue of plants (Burducea et al. 2019, Gill and Tuteja 2010). Results in our study also showed that SOD activity was the highest among the detected four enzymes and varied with genotypes and growth period (Fig.5). These suggested that SOD might be the main enzyme to interfere and metabolize excess $\mathrm{H}_{2} \mathrm{O}_{2}$ and $\mathrm{O}_{2}$ at a high rate (Burducea et al. 2019, Gill and Tuteja 2010).

Variation of phytochemical content was also influenced by genotype and environmental conditions during growth period (Zhou et al. 2019, Liu et al. 2018a, 2018b, Tohidi et al. 2017, Itidel et al. 2013, Sati et al. 2013). Djerrad et al. (2015) reported geographic variation and environmental conditions had important effect on essential oils in Pinus halepensis. Deng et al. (2015) indicated that genotype and growth environment significantly affected flavonoid accumulation of $C$. paliurus, with environmental effects being more predominant. Under the same environment, genotypes had a significant role in flavonoid accumulation of C. paliurus (Fang et al. 2011). In accordance with previous researches (Djerrad et al. 2015, Cui et al. 2013, Fang et al. 2011, Sosa et al. 2005, Hare 2002), our findings also showed that variations in TP, TF and TT content were found from different genotypes and phytochemical accumulation was related with environmental factors during growth period(Fig.6, Fig.8).

According to our results, leaves of $C$. paliurus were rich in flavonoid and polysaccharides, which was consistent with previous works (Shang et al. 2018, Liu et al. 2018a, 2018b, Yang et al. 2017, Xie et al. 2012, Fang et al. 2011). But total flavonoid content in the $C$. paliurus was far beyond that of previous studies (Liu et al. 2018a, 2018b, Zhou et al. 2019), however both of polysaccharids content and total triterpenoid content was lower than previous results (Zhou et al. 2019, Deng et al. 2017). This may be caused by difference in the extraction method.

Higher content of $\mathrm{K}$ and $\mathrm{Ca}$ in leaf of $\mathrm{C}$. paliurus (Fig.8) were clustered into one group and had significant negative with temperature and precipitation (Tab.4), suggesting that relatively large amount of Ca and K could act on similar biological metabolize (Coskun et al. 2013, Gattward et al. 2012). These were also observed in the other results by Peiter (2011), Ahmad and Maathuis (2014). Mg directly or indirectly participates in biological processes in plants, like the synthesis of chlorophyll (Masuda 2008), Ribulose-1,5-bisphosphat-carboxylase/-oxygenase (Rubisco) activity (Portis 2003). Mg deficiency reduced the absorption and utilization of light energy, which induced the production of reactive oxygen species (ROS) (Guo et al. 2016). Antioxidant enzyme developed in plants is expected to cope with the harmful effects of ROS, like SOD and CAT(Tewari et al. 2004; Tang et al. 2012).This could be a reason that Mg had positive relation with SOD and CAT, especially one group was formed between Mg and CAT(Tab.4, Fig.8).

Between the four tested mineral elements and three kinds of phytochemical, Ca and $\mathrm{Mg}$ was significant positively correlated with polysaccharides and total flavonoid without fertilization condition, respectively, which was disagreement with Deng et al. (2019b) who reported Ca and Mg had a significant negatively correlation with total flavonoid accumulation under five nitrogen fertilization levels (Deng et al. 2019b). This could be caused by nitrogen availability, which influence nutrient balance and further affected phytochemical accumulation in C. paliurus (Deng et al. 2019b).

\section{Conclusions}

Plants of $C$. paliurus of six genotypes were conserved in a clonal seed orchards at Quanzhou, Fujian province. Variations in plant growth and physiological changes in leaf were analyzed and results showed that (1) plant growth among 6 genotypes was different in plant height and basal diameter. (2) Difference in WC and TSS content among 6 genotypes varied from April to October. Four kinds of antioxidant enzyme and mineral element content was in order with SOD $\triangle P P O \triangle P O D \otimes C A T, C a \triangle K \otimes M g \triangle N a$, respectively. Total flavonoid accumulation in leaf was the highest, then was polysaccharides, and finally was total triterpenoid. (3) Both of plant growth and physiological index had relation with environmental factors (mean temperature, precipitation, sunshine hours) and various physiological index also related with each other by relation analysis. These results suggested that plants of 6 genotypes had a better adaptation in CSO by physiological changes during growth period and different genotypes varied in plant growth and nutrient accumulation. Therefore, results from this study provide a foundation for ex situ conservation management of Cyclocarya species and selection for breeding programs.

\section{Declarations}

\section{Authors' contributions}

YF designed the work plan and preparation of manuscript. JPH carried out the construction of a clonal seed orchard of $C$. paliurus and carried out mineral nutrient content determination, GXL measured water content and total soluble sugar content in the laboratory, ChQZh determined antioxidant enzyme activity, XYY performed phytochemical content measurement, XFL performed the statistical analysis.

\section{Fundings}

This work was funded by Fujian Province Science and Technology Project (No. 2017N0028) and Quanzhou Science and Technology Project (No. 2018N007).

\section{Availability of data and materials}

The data that support the findings of this study are available from the authors (School of Resource and Environmental Science, Quanzhou Normal University China) upon reasonable requests and with permission from Quanzhou Normal University (China).

\section{Ethics approval and consent to participate}


Not applicable.

\section{Consent for publication}

Not applicable.

\section{Competing interests}

The authors declare that they have no competing interests.

\section{References}

1. Ahmad I, Maathuis FJM (2014) Cellular and tissue distribution of potassium: physiological relevance, mechanisms and regulation. J of Plant Physiol 171:708-714

2. Babu Umesh MS, Nautiyal S (2015) Conservation and management of forest resources in India: ancient and current perspectives natural resources. 6 : 256-272

3. Baghour M, Moreno DA, Villora G, Lopez-Cantarero I, Hernandez J, Castilla N, Romero L (2002) Root-zone temperature influences the distribution of Cu and $\mathrm{Zn}$ in potato-plant organs. $\mathrm{J}$ of Agri Food Chem 50:140-146

4. Baghour M, Ragala L, Moreno DA, Villora G, Hernandez J, Castilla N, Romero L (2003) Effect of root zone temperature on accumulation of molybdenum and nitrogen metabolism in potato plants. $\mathrm{J}$ of Plant Nutr 26:443-461

5. Burducea M, Zheljazkov DV, Lobiuc A, Pintilie AC, Virgolici M, Silion M, Asandulesa M, Burducea I, Zamfirache MM (2019) Biosolids application improves mineral composition and phenolic profile of basil cultivated on eroded soil. Sci Horti 249:407-418

6. Cao Y, Fang S, Yin Z, Fu X, Shang X, Yang W, Yang H (2017) Chemical fingerprint and multicomponent quantitative analysis for the quality evaluation of Cyclocarya paliurus leaves by HPLC-Q-TOF-MS. Mol 22(11):1927

7. Corlett RT (2016) Plant diversity in a changing world. Plant Div 1:11-18

8. Coskun D, Britto DT, Jean YK, Kabir I, Tolay I, Torun AA, Kronzucker HJ (2013) $\mathrm{K}^{+}$efflux and retention in response to NaCl stress do not predict salt tolerance in contrasting genotypes of rice (Oryza sativa L.). PLoS One 8:1-16

9. Cui G, Zhang W, Zhang A, Mu H, Ba H, Duan J, Wu C (2013) Variation in antioxidant activities of polysaccharides from Fructus Jujubae in South Xinjiang area. International $\mathrm{J}$ of Bio Macrom 57:278-284

10. Chaloupkova K, Stejskal J, El-Kassaby YA, Frampton J, Lstiburek M (2019) Current advances in seed orchard layouts: two case studies in conifers. Forests 10:93

11. Deng B, Li YY, Lei G, Liu GH (2019a) Effects of nitrogen availability on mineral nutrient balance and flavonoid accumulation in Cyclocarya paliurus. Plant Physiol Biochem 135:111-118

12. Deng B, Li YY, Xu DD, Ye QQ, Liu GH (2019b) Nitrogen availability alters flavonoid accumulation in Cyclocarya paliurus via the effects on the internal carbon/nitrogen balance. Sci Rep 9:2370

13. Deng B, Fang ShZ, Shang XL, Fu XX, Li Y (2017) Influence of provenance and shade on biomass production and triterpenoid accumulation in Cyclocarya paliurus. Agro Sys. doi:10.1007/s10457-017-0138-x

14. Deng B, Cao YN, Fang ShZ, Shang XL, Yang WX, Qian ChY (2015) Variation and stability of growth and leaf flavonoid content in Cyclocarya paliurus across environments. Indus Crops Prod 76:386-393

15. Deng B, Fang ShZ, Yang WX, Tian Y, Shang XL (2014) Provenance variation in growth and wood properties of juvenile Cyclocarya paliurus. New Forests: doi 10.1007/s11056-014-9424-x

16. Djerrad Z, Kadik L, Djouahri A (2015) Chemical variability and antioxidant activities among Pinus halepensis Mill. essential oils provenances, depending on geographic variation and environmental conditions. Indus Crops Prod 74:440-449

17. Enßlin A, Sandner TM, Matthies D (2011) Consequences of ex situ cultivation of plants: genetic diversity, fitness and adaptation of the monocarpic Cynoglossum officinale L. in botanic gardens. Biol Cons 144(1):272-278

18. Fang SZ, Yang WX, Chu XL, Shang XL, She CQ, Fu XX (2011) Provenance and temporal variations in selected flavonoids in leaves of Cyclocarya paliurus. Food Chem 124:1382-1386

19. Fang ShZ, Wang JY, Wei ZhY, Zhu ZhX (2006) Methods to break seed dormancy in Cyclocarya paliurus (Batal) Iljinskaja. Sci Horti 110:305-309

20. Feng Y, Lin XL, Qian LW, Hu NJ, KuangChF,Li XF, Li Zh, Huang LR, Liu MM (2020) Morphological and physiological variations of Cyclocarya paliurus under different soil water capacities. Physiol Molr Biol of Plants 26(8):1663-1674

21. Gattward JN, Almeida AAF, Souza JO, Gomes FP, Kronzucker HJ (2012) Sodium-potassium synergism in Theobroma cacao: stimulation of photosynthesis, water-use efficiency and mineral nutrition. Phy of Plant 146:350-362

22. Gill SS, Tuteja N (2010) Reactive oxygen species and antioxidant machinery in abiotic stress tolerance in crop plants. Plant Phy Biochem 48(12):909930

23. Giertych M (1975) Seed orchard designs. For Com Bull: 25-37

24. Guo W, Nazim H, Liang Z, Yang D (2016) Magnesium deficiency in plants: an urgent problem. Crop J 4:83-91

Page 6/14 
25. Glikson A (2012) Is another mass extinction event on the way? The conservation

26. Hare JD (2002) Geographic and genetic variation in the leaf surface resin components of Mimulus aurantiacus, from southern California. Biochem Syst Ecol 30(4):281-296

27. Itidel C, Chokri M, Mohamed B, Yosr Z (2013) Antioxidant activity, total phenolic and flavonoid content variation among Tunisian natural populations of Rhu tripartite (Ucria) Grande and Rhus pentaphylla Desf. Indus Crops Prod 51:171-177

28. Jiang C, Yao N, Wang QQ, Zhang JH, Sun Y, Xiao N, Liu K, Huang F, Fang ShZ, Shang XL, Liu BL, Ni YCh, Yin ZhQ, Zhang J (2014) Cyclocarya paliurus extract modulates adipokine expression and improves insulin sensitivity by inhibition of inflammation in mice. Journal of Ethnopharmacol 153(2): 344-351

29. Li XCh, Fu XX, Shang XL, Yang WX, Fang ShZ (2017) Natural population structure and genetic differentiation for heterodicogamous plant: Cyclocarya paliurus (Batal.) Iljinskaja (Juglanndaceae). Tree Gene and Geno 13: 80

30. Li HSh (2000) Principles and techniques of plant physiological biochemical experiment. Higher education press, Beijing, pp 195-197

31. Liu Y, Fang ShZ, Zhou MM, Shang XL, Yang WX, Fu XX (2018a) Geographic variation in water-soluble polysaccharide content and antioxidant activities of Cyclocarya paliurus leaves. Indus Crops Prod 121:180-186

32. Liu Y, Chen P, Zhou MM, Wang TL, Fang ShZ, Shang XL, Fu XX (2018b) Geographic variation in the chemical composition and antioxidant properties of phenolic compounds from Cyclocarya paliurus (Batal.) Iljinskaja leaves. Mol 23:2440

33. Liu Y, Fang ShZ, Yang WX, Shang XL, Fu XX (2018c) Light quality affects flavonoid production and related gene expression in Cyclocarya paliurus. J of Photochem Photobiol B: Biol 179:66-73

34. Masuda T (2008) Recent overview of the Mg branch of the tetrapyrrole biosynthesis leading to chlorophylls. Photosyn Res $96: 121-143$

35. Peng WW, Zhao SM, Ji ChJ, Huo GH, Wan ChP, Li YY, Zhang YL (2019) Cyclopatitins A and B, nortriterpenoids from aerial parts of Cyclocarya paliurus. Phytochem Lett 31:114-117

36. Karthikeya S (2007) What are the threats to biodiversity. Cen for edu and Environ

37. Portis ARJ (2003) Rubisco activase-rubisco's catalytic chaperone. Photosyn Res 75:11-27

38. Peiter E (2011) The plant vacuole: emitter and receiver of calcium signals. Cell Cal 50:120-128

39. Pritchard HW, Perner H, Seaton PT, Hu H (2010) Ex situ conservation of orchids in a warming world. The Botan Rev 76(2):193-203

40. Sati P, Pandey A, Rawat S, Rani A (2013) Phytochemicals and antioxidants in leaf extracts of Ginkgo biloba with reference to location, seasonal variation and solvent system. J of Pharm Res 7(9):804-809

41. Sosa T, Alías JC, Escudero JC, Chaves N (2005) Interpopulational variation in the flavonoid composition of Cistus ladanifer L. exudate. Biochem Sys Ecol 33(4):353-364

42. Schachtman DP, Kumar R, Schroeder Jl, Marsh EL (1997) Molecular and functional characterization of a novel low-affinity cation transporter (LCTI) in higher plants. Proceed of the Nat Acad of Sci USA 94:11079-11084

43. Shang XCh, Tan JN, Du YM, Liu XM, Zhang ZhF (2018) Environmentally-friendly extraction of flavonoids from Cyclocarya paliurus (Batal.) Iljinskaja leaves with deep eutectic solvents and evaluation of their antioxidant activities. Mol 23:2110

44. Stein WI, Edwards JL, Tinus RW (1975) Outlook for container-grown seedling use in reforestation. J of For 73:337-341

45. Tang N, Li Y, Chen LS (2012) Magnesium deficiency-induced impairment of photosynthesis in leaves of fruiting Citrus reticulata trees accompanied by up-regulation of antioxidant metabolism to avoid photo-oxidative damage. J of Plant Nut Soil Sci 175:784-793

46. Tewari RK, Kumar P, Tewari N, Srivastava S, Sharma PN (2004) Macronutrient deficiencies and differential antioxidant responses-influence on the activity and expression of superoxide dismutase in maize. Plant Sci 166:687-694

47. Tohidi B, Rahimmalek M, Arzani A (2017) Essential oil composition, total phenolic, flavonoid contents, and antioxidant activity of Thymus species collected from different regions of Iran. Food Chem 220:153-161

48. Wang ZJ, Xie JH, Yang YJ, Zhang F, Wang SN, Wu T, Shen M, Xie MY (2017) Sulfated Cyclocarya paliurus polysaccharides markedly attenuates inflammation and oxidative damage in lipopolysaccharide-treated macrophage cells and mice. Sci Rep 7:40402

49. Xie JH, Liu X, Shen MY, Nie SP, Zhang H, Li C, Gong DM, Xie MY (2013) Purification physicochemical characterization and anticancer activity of a polysaccharides from Cyclocarya paliurus leaves. Food Chem 136(3-4):1453-1460

50. Xie JH, Shen MY, Xie MY, Nie SP, Chen Y, Li C, Huang FD, Wang YX (2012) Ultrasonicassisted extraction, antimicrobial and antioxidant activity of Cyclocarya paliurus (Batal.) Iljinskaja polysaccharides. Carbohyd Polymers 89:177-184

51. Xiong L, Ouyang KH, Jiang Y, Yang ZhW, Hu WB, Chen H, Wang N, Xin WJ (2018) Chemical composition of Cyclocarya paliurus polysaccharide and inflammatory effects in lipopolysaccharide-stimulated RAW264.7 macrophage. Inter J Bio Macromol 107:1898-1907

52. Yang WX, Liu Y, Fang ShZ, Ding HF, Zhou MM, Shang XL (2017) Variation in growth, photosynthesis and water-soluble polysaccharide of Cyclocarya paliurus under different light regimes. iForest 10:468-474

53. Zobel BJ, Barber J, Brown CL, Perry TO (1958) Seed orchards-their concept and management. J of Forest 56:815-825

54. Zhu KN, Jiang CH, Tian YS, Xiao N, Wu ZF, Ma YL, Lin Z, Fang SZ, Shang XL, Liu K, Zhang J, Liu BL, Yin ZQ (2015) Two triterpeniods from Cyclocarya paliurus (Batal) Iljinsk (Juglandaceae) promote glucose uptake in 3T3-L1 adipocytes: the relationship to AMPK activation. Phytomed 22:837-846

55. Zhou MM, Lin Y, Fang ShZ, Liu Y, Shang XL (2019) Phytochemical content and antioxidant activity in aqueous extracts of Cyclocarya paliurus leaves collected from different population. Peer J 7:e6492 


\section{Tables}

Tab.1 Environmental parameters in the experimental site

\begin{tabular}{|c|c|c|c|c|c|c|c|c|}
\hline \multirow[t]{2}{*}{ Indexes } & \multicolumn{3}{|l|}{ Year } & \multirow[t]{2}{*}{ Indexes } & \multicolumn{4}{|c|}{ Month } \\
\hline & 2017 & 2018 & 2019 & & Aprill $^{a}$ & $J_{u n e}^{a}$ & August $^{\mathrm{a}}$ & October $^{\mathrm{a}}$ \\
\hline AT $\left({ }^{\circ} \mathrm{C}\right)$ & 20.6 & 20.4 & 18.6 & $\mathrm{~T}\left({ }^{\circ} \mathrm{C}\right)$ & 18.4 & 23.5 & 24.7 & 18.1 \\
\hline $\mathrm{AP}(\mathrm{mm})$ & 1296.4 & 1794.7 & 1570.7 & $\mathrm{P}(\mathrm{mm})$ & 64.3 & 227.7 & 353.7 & 53 \\
\hline AS(h) & 1874.6 & 1825.6 & 1600.6 & $S(h)$ & 152 & 123.8 & 177 & 159.2 \\
\hline
\end{tabular}

${ }^{a}$ Climatic parameters were recorded in 2018. AT mean annual mean temperature; AP mean annual precipitation; AS mean annual sunshine hours. T mean average temperature, $\mathrm{P}$ mean percipitation, $\mathrm{S}$ mean sunshine hours.

Tab.2 Variation in plant growth index among six genotypes of Cyclocarya paliurus

\begin{tabular}{|llllllll|}
\hline Index & Year & FJ & JX & WF & TG & JH & AJ \\
\hline $\mathrm{H}$ & 2017 & $10.67 \pm 3.34 \mathrm{~b}$ & $15.70 \pm 1.51 \mathrm{c}$ & $7.08 \pm 0.79 \mathrm{c}$ & $18.00 \pm 4.47 \mathrm{c}$ & $18.98 \pm 1.53 \mathrm{~b}$ & $10.71 \pm 0.29 \mathrm{c}$ \\
\cline { 2 - 8 } & 2018 & $48.15 \pm 16.46 \mathrm{~b}$ & $88.75 \pm 6.51 \mathrm{~b}$ & $100.06 \pm 7.05 \mathrm{~b}$ & $59.42 \pm 2.98 \mathrm{~b}$ & $72.32 \pm 12.19 \mathrm{~b}$ & $72.57 \pm 15.50 \mathrm{~b}$ \\
\cline { 2 - 8 } & 2019 & $300.17 \pm 29.33 \mathrm{a}$ & $148.33 \pm 18.00 \mathrm{a}$ & $269.16 \pm 28.13 \mathrm{a}$ & $168.29 \pm 14.48 \mathrm{a}$ & $236.82 \pm 47.19 \mathrm{a}$ & $133.58 \pm 27.42 \mathrm{a}$ \\
\hline $\mathrm{BD}$ & 2017 & $3.39 \pm 1.27 \mathrm{~b}$ & $2.56 \pm 0.79 \mathrm{c}$ & $2.62 \pm 0.76 \mathrm{c}$ & $1.54 \pm 0.45 \mathrm{c}$ & $1.80 \pm 0.22 \mathrm{c}$ & $1.11 \pm 0.14 \mathrm{c}$ \\
& 2018 & $7.92 \pm 4.24 \mathrm{~b}$ & $9.07 \pm 1.76 \mathrm{~b}$ & $10.36 \pm 1.88 \mathrm{~b}$ & $8.13 \pm 1.20 \mathrm{~b}$ & $9.74 \pm 1.61 \mathrm{~b}$ & $9.03 \pm 1.81 \mathrm{~b}$ \\
& 2019 & $27.12 \pm 3.73 \mathrm{a}$ & $21.84 \pm 1.49 \mathrm{a}$ & $20.49 \pm 4.52 \mathrm{a}$ & $19.78 \pm 1.63 \mathrm{a}$ & $53.19 \pm 5.45 \mathrm{a}$ & $25.27 \pm 1.09 \mathrm{a}$ \\
\hline
\end{tabular}

$\mathrm{H}$ denoted the net height of every plants, BD denoted the net basal diameter of every plants. FJ denoted Yongchun, Fujian provenance; JX denoted Jinggangshan, Jiangxi provenance; AJ denoted Anji, Zhejiang provenance; TG denoted Tonggu, Jiangxi provenance; JH denoted Jianhe, Guizhou provenance; WF denoted Wufeng, Hubei provenance.

Tab.3 Correlation between plant growth and environmental factors

\begin{tabular}{|llllll|}
\hline Factors & $\mathrm{H}$ & $\mathrm{BD}$ & $\mathrm{AT}$ & $\mathrm{AP}$ & $\mathrm{AS}$ \\
\hline $\mathrm{H}$ & 1.00 & $0.83^{\star \star}$ & -0.10 & -0.19 & $-0.90^{\star \star}$ \\
\hline $\mathrm{BD}$ & & 1.00 & -0.06 & -0.22 & $-0.85^{\star \star}$ \\
\hline AT & & & 1.00 & $-0.95^{\star \star}$ & -0.02 \\
AP & & & & 1.00 & 0.35 \\
AS & & & & & 1.00 \\
\hline
\end{tabular}

Note: $\mathrm{H}, \mathrm{BD}, \mathrm{AT}, \mathrm{AP}, \mathrm{AS}$ denotes plant height, plant basal diameter, annual mean temperature, annual precipitation, annual sunshine light, respectively. *means difference level at $0.05,{ }^{\star \star}$ means difference level at 0.01 .

Tab.4 Correlation between environmental factors and physiological index 


\begin{tabular}{|c|c|c|c|c|c|c|c|c|c|c|c|c|c|c|c|c|}
\hline Factors & $\mathrm{T}$ & $\mathrm{P}$ & $S$ & WC & TSS & SOD & CAT & POD & PPO & $\mathrm{K}$ & $\mathrm{Na}$ & $\mathrm{Ca}$ & $\mathrm{Mg}$ & TP & TF & TT \\
\hline $\mathrm{T}$ & 1 & & & & & & & & & & & & & & & \\
\hline$P$ & $0.97^{\star *}$ & 1 & & & & & & & & & & & & & & \\
\hline S & -0.01 & 0.23 & 1 & & & & & & & & & & & & & \\
\hline WC & -0.04 & -0.19 & $-0.62^{\star \star}$ & 1 & & & & & & & & & & & & \\
\hline TSS & -0.11 & 0 & 0.44 & -0.60 ** & 1 & & & & & & & & & & & \\
\hline SOD & 0.43 & 0.41 & -0.07 & 0.25 & -0.35 & 1 & & & & & & & & & & \\
\hline CAT & 0.21 & 0.18 & -0.09 & 0.15 & -0.1 & 0.02 & 1 & & & & & & & & & \\
\hline POD & 0.19 & 0 & $-0.73^{\star \star}$ & 0.37 & -0.34 & 0.13 & 0.12 & 1 & & & & & & & & \\
\hline PPO & -0.04 & -0.02 & 0.08 & -0.17 & 0.1 & 0.32 & -0.28 & -0.21 & 1 & & & & & & & \\
\hline K & $-0.47 *$ & $-0.57 \star \star$ & -0.42 & $0.48 *$ & -0.05 & $-0.50 *$ & 0.13 & 0.4 & -0.35 & 1 & & & & & & \\
\hline $\mathrm{Na}$ & -0.17 & -0.26 & -0.41 & 0.49 * & -0.27 & 0.32 & 0.34 & 0.17 & 0.04 & 0.21 & 1 & & & & & \\
\hline $\mathrm{Ca}$ & $-0.54 *$ & $-0.48^{*}$ & 0.17 & -0.2 & 0.09 & -0.31 & -0.11 & -0.42 & 0.23 & -0.05 & 0.12 & 1 & & & & \\
\hline $\mathrm{Mg}$ & -0.34 & -0.4 & -0.27 & 0.43 & 0 & 0.01 & 0.19 & -0.06 & -0.17 & 0.37 & $0.58^{\star \star}$ & 0.13 & 1 & & & \\
\hline TP & $-0.80 \star \star$ & $-0.72 \star \star$ & 0.19 & 0.03 & -0.01 & -0.03 & -0.01 & -0.31 & 0.08 & 0.18 & 0.31 & $0.56^{*}$ & 0.29 & 1 & & \\
\hline TF & $-0.48^{*}$ & $-0.53^{*}$ & -0.27 & 0.19 & -0.15 & 0.21 & -0.25 & 0.04 & 0.04 & 0.09 & $0.59 \star \star$ & 0.42 & $0.45^{\star}$ & $0.56^{\star \star}$ & 1 & \\
\hline TT & 0.02 & 0.14 & $0.49 *$ & -0.60 ** & 0.4 & -0.14 & -0.11 & -0.25 & -0.12 & -0.09 & -0.15 & 0.1 & -0.28 & 0.12 & 0.18 & 1 \\
\hline
\end{tabular}

T mean average temperature, P mean percipitation, S mean sunshine hours, WC mean water content, TSS mean total soluble sugar content, TT denoted total triterpenoid, TF denoted total flavonoid, TP denoted polysaccharide.

Figures 

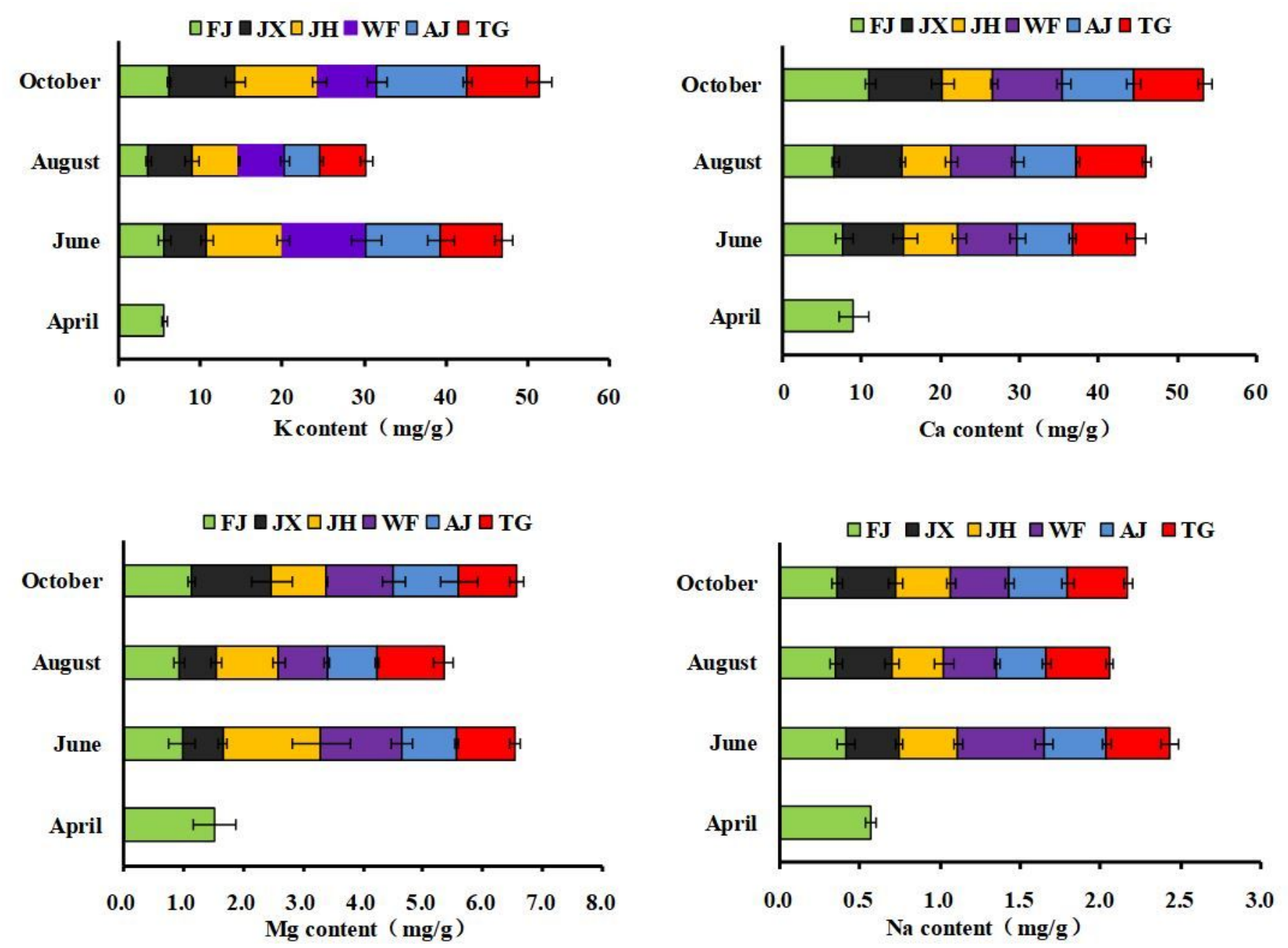

Figure 1

Mineral content in leaf among six genotypes of Cyclocarya paliurus FJ denoted Yongchun, Fujian provenance; JX denoted Jinggangshan, Jiangxi provenance; AJ denoted Anji, Zhejiang provenance; TG denoted Tonggu, Jiangxi provenance; JH denoted Jianhe, Guizhou provenance; WF denoted Wufeng, Hubei provenance. 

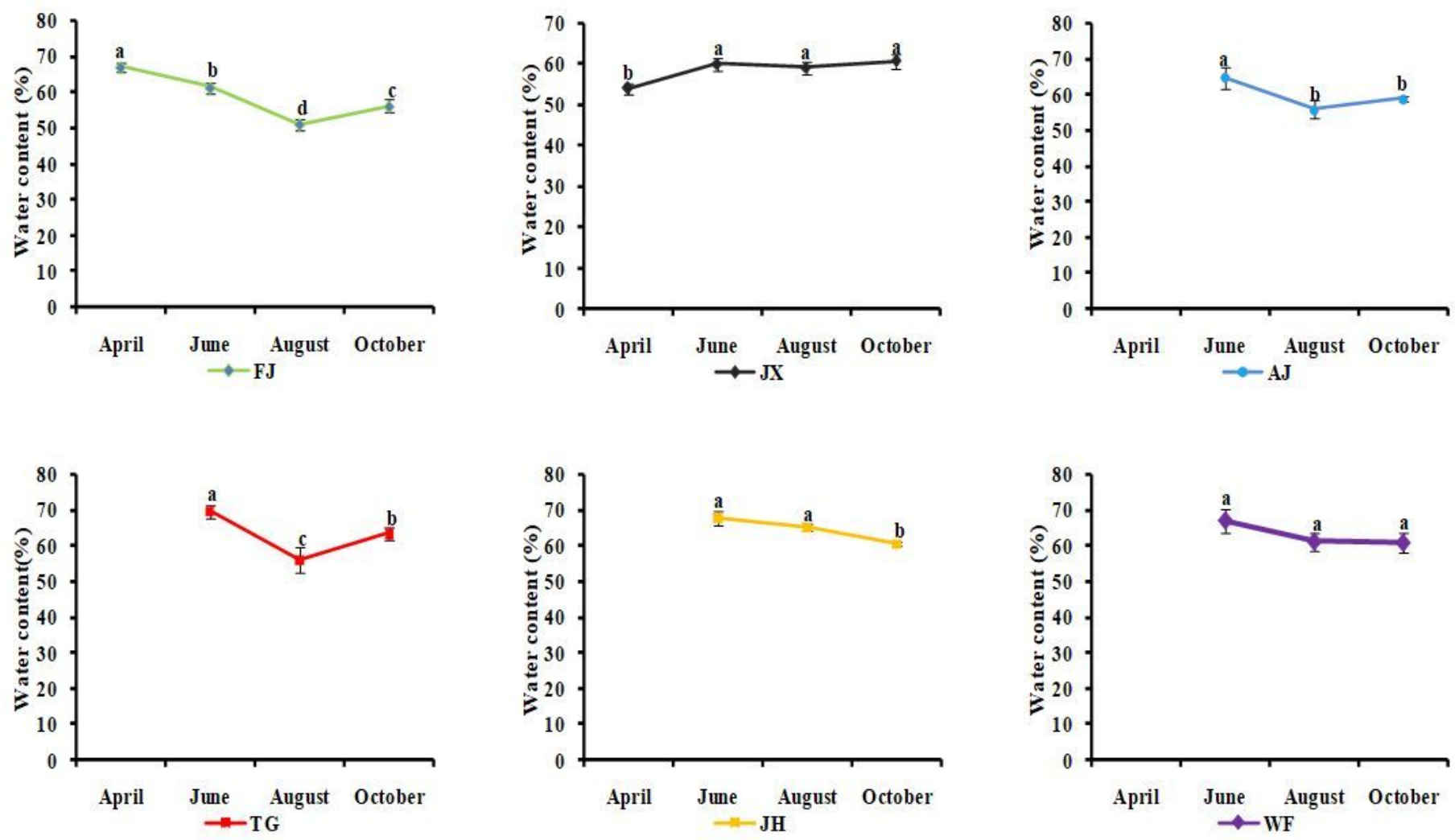

Figure 1

Water content in leaves among six genotypes of Cyclocarya paliurus FJ denoted Yongchun, Fujian provenance; JX denoted Jinggangshan, Jiangxi provenance; AJ denoted Anji, Zhejiang provenance; TG denoted Tonggu, Jiangxi provenance; JH denoted Jianhe, Guizhou provenance; WF denoted Wufeng, Hubei provenance.

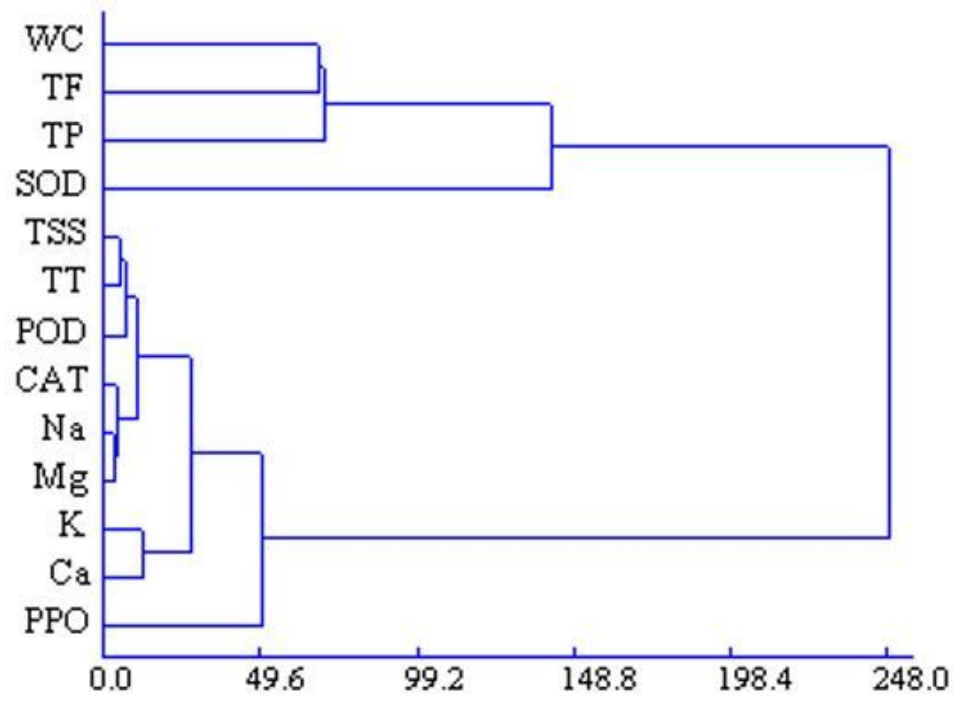

Figure 1

Cluster analysis of different studied factors 


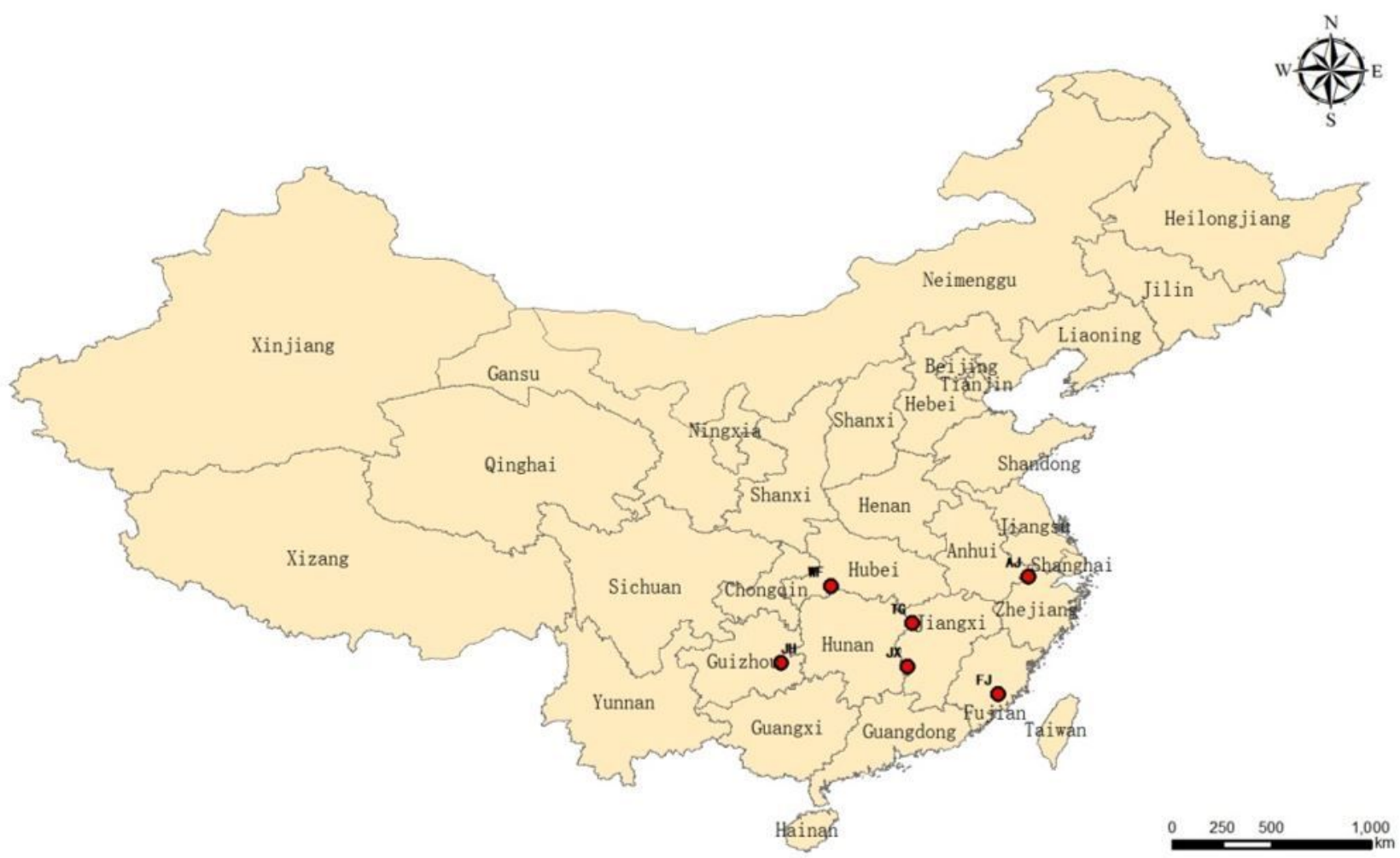

Figure 1

Information about seed from six genotypes of Cyclocarya paliurus FJ denoted Yongchun, Fujian provenance; JX denoted Jinggangshan, Jiangxi provenance; AJ denoted Anji, Zhejiang provenance; TG denoted Tonggu, Jiangxi provenance; JH denoted Jianhe, Guizhou provenance; WF denoted Wufeng, Hubei provenance. Note: The designations employed and the presentation of the material on this map do not imply the expression of any opinion whatsoever on the part of Research Square concerning the legal status of any country, territory, city or area or of its authorities, or concerning the delimitation of its frontiers or boundaries. This map has been provided by the authors. 

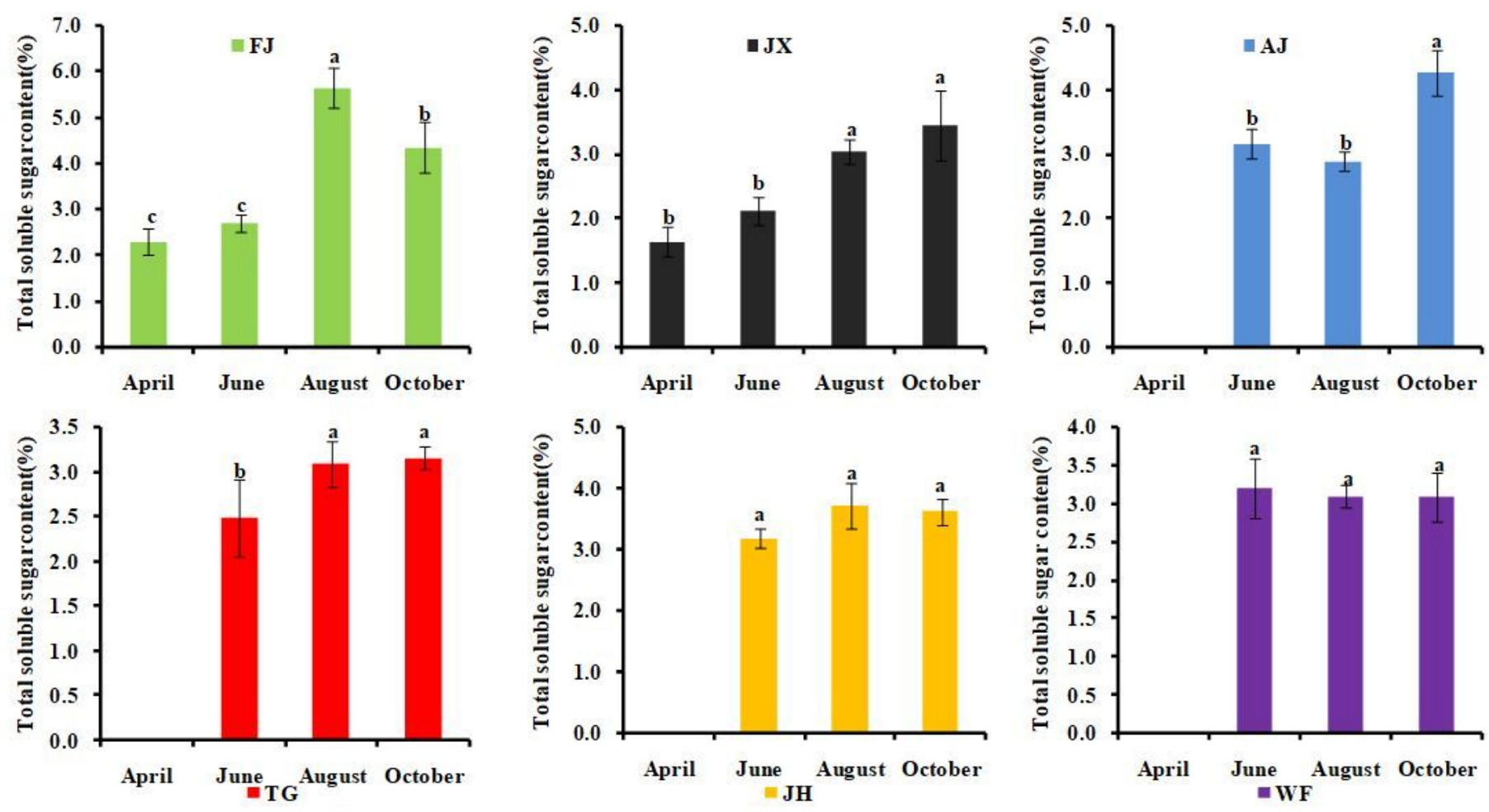

Figure 1

Total soluble sugar content in leaf among six genotypes of Cyclocarya paliurus FJ denoted Yongchun, Fujian provenance; JX denoted Jinggangshan, Jiangxi provenance; AJ denoted Anji, Zhejiang provenance; TG denoted Tonggu, Jiangxi provenance; JH denoted Jianhe, Guizhou provenance; WF denoted Wufeng, Hubei provenance.
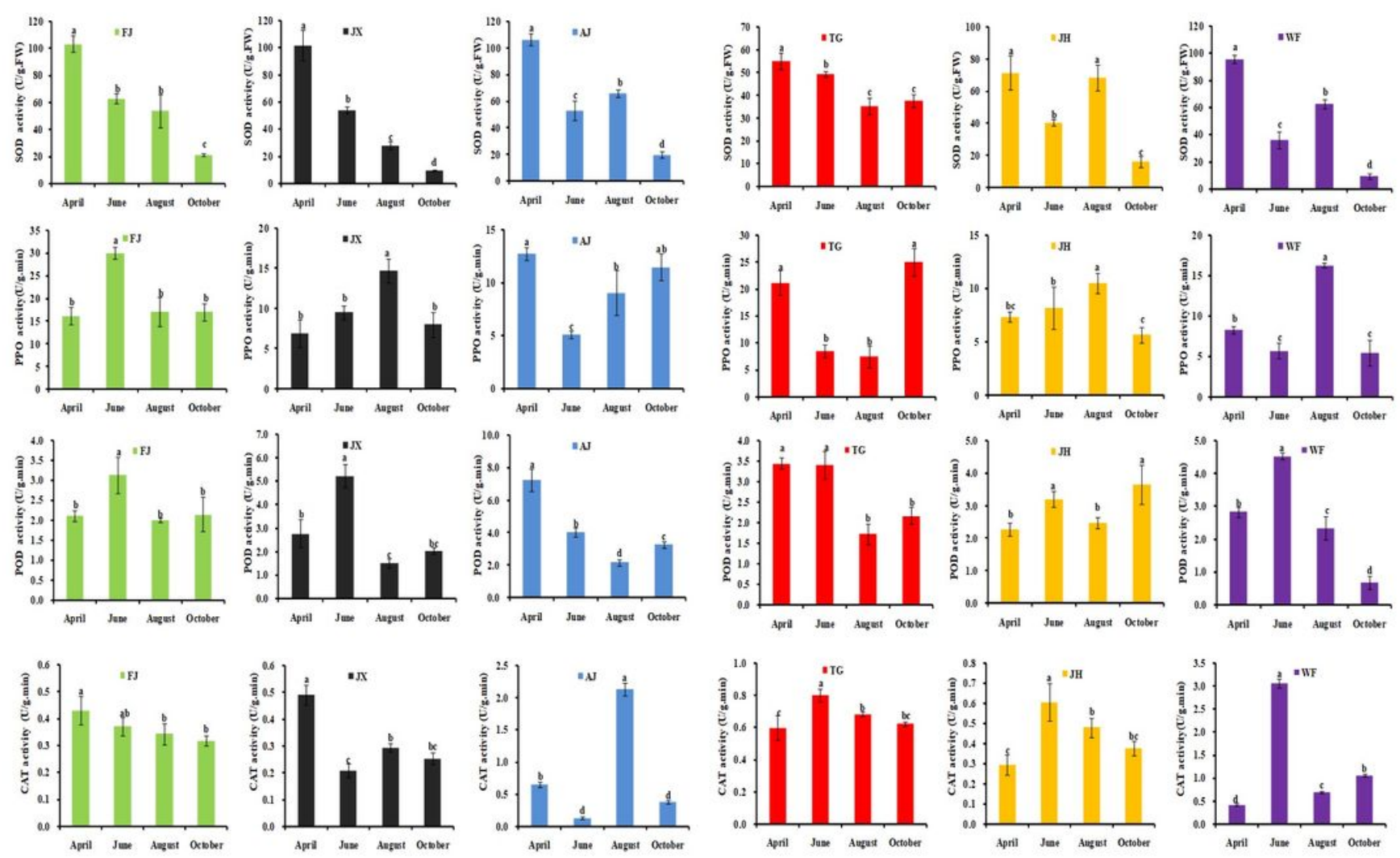
Figure 1

Variation in antioxidant enzyme activity among six genotypes of Cyclocarya paliurus FJ denoted Yongchun, Fujian provenance; JX denoted Jinggangshan, Jiangxi provenance; AJ denoted Anji, Zhejiang provenance; TG denoted Tonggu, Jiangxi provenance; JH denoted Jianhe, Guizhou provenance; WF denoted Wufeng, Hubei provenance.
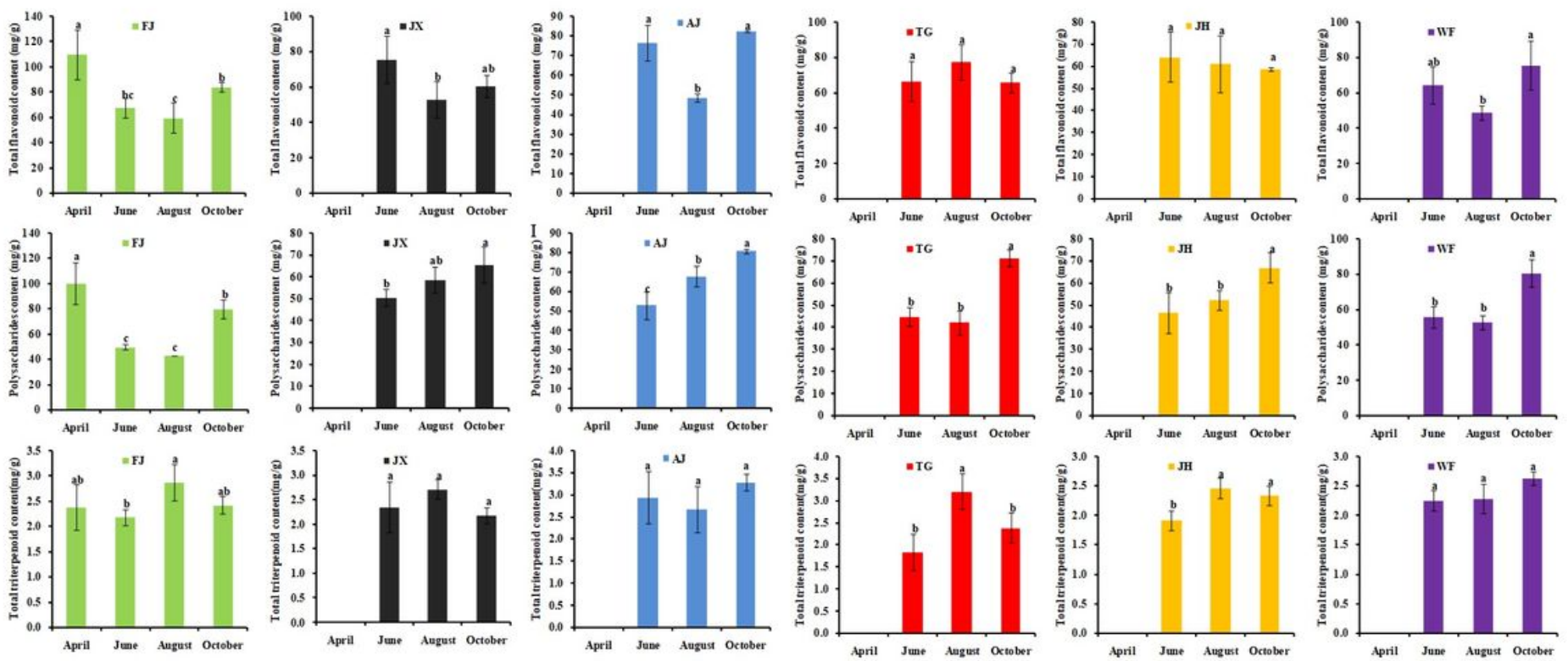

\section{Figure 1}

Variation in phytochemical accumulation among six genotypes of Cyclocarya paliurus FJ denoted Yongchun, Fujian provenance; JX denoted Jinggangshan, Jiangxi provenance; AJ denoted Anji, Zhejiang provenance; TG denoted Tonggu, Jiangxi provenance; JH denoted Jianhe, Guizhou provenance; WF denoted Wufeng, Hubei provenance.

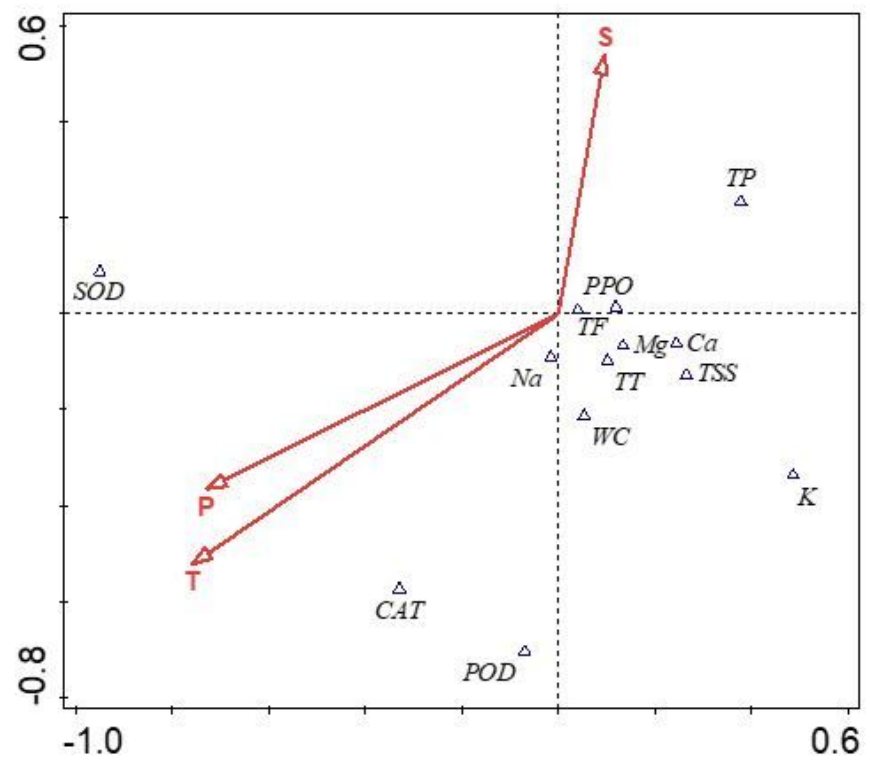

\section{Figure 1}

Canonical correspondence analysis between environment factors and different parameters. T mean average temperature, $\mathrm{P}$ mean percipitation, $\mathrm{S}$ mean sunshine hours, WC mean water content, TSS mean total soluble sugar content, TT denoted total triterpenoid, TF denoted total flavonoid, TP denoted polysaccharides. 